\title{
دراسة حالة عن مميزات المدرسة الثانوية الدينية الأولى (MAN I) يوجياكارتا \\ جيجين موسفاه
}

مدرس في كلية التربية والتعليم جامعة شريف هداية الله الإسلامية بجاكرتا

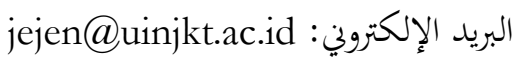

\section{ملخص البحث}

ينطلق هذا البحث من الواقع أن معظم المدارس الإسلامية تتأخر من المدارس العامة وتنخفض من

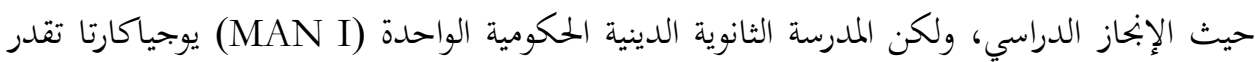

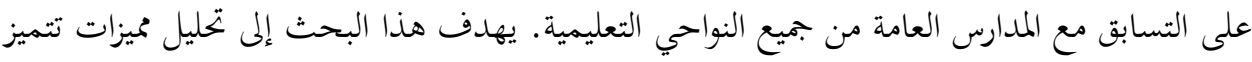

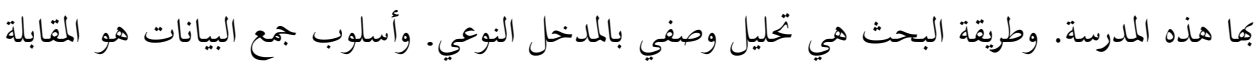

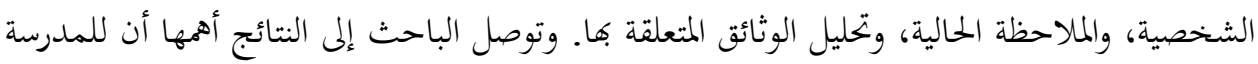

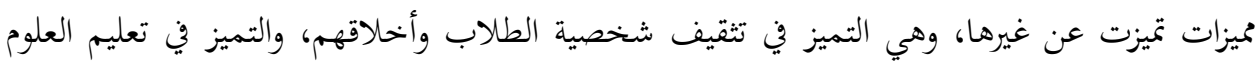

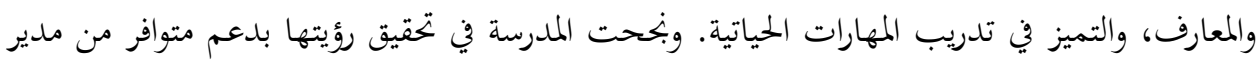

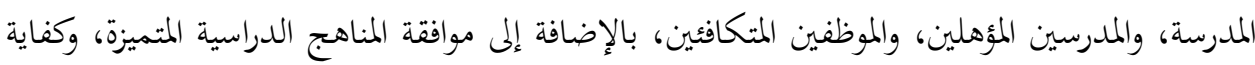
المرافق المدرسية، والأنشطة الدراسية.

المصطلحات الرئيسية: المدرسة الدينية المتفوقة، تميز الشخصية والأخلاق، تميز العلوم والمعارف، تميز المهارات الحياتية.

\section{ABSTRACT}

This study departed from a reality that in the middle to low quality and learning achievement of madrasas, Madrasah Aliyah I (MAN I) Yogyakarta is a madrassa that can compete with the top schools in general. This study aims to analyze the various advantages of the Madrasah Aliyah I (MAN I) Yogyakarta. The method used in this research is descriptive method with qualitative approach. Data collection techniques are personal interviews, observation, and various documents related to the study material. Based on the research results, we concluded that the school has many advantages over other schools, among them cultivate a good personality, excel in science, and 
Jejen Musfah

excel in the field of life skills. This school was considered a success in realizing its vision primarily because it is supported by the commitment of the principal, the competence of the teachers and administrative staff. In addition, a lack of compatibility between the vision and mission of the school curricula, completeness educational facilities and learning activities.

Keywords: Excellent Madrasah, Excellence of Character, Excellence of Science, Excellence of Life Skills

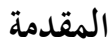

التربية هي محاولة لتشكيل أفراد الجيل (الطلاب) أشخاصا ذوي علوم ومعارف ومهارات حياتية. هذه المحاولة لا تتم إلا بتعامل الطلاب في ظروف المريل المدارس الدينية الجيدة. وينبغي للمدارس

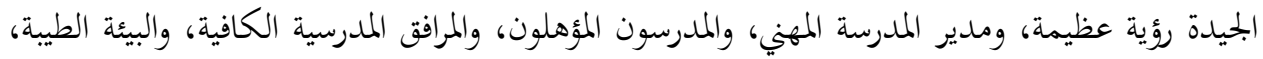

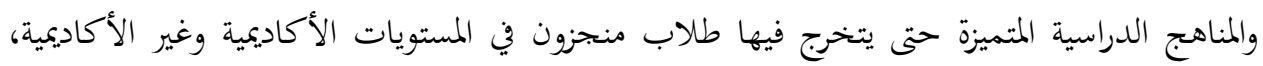
وطنية كانت أو إقليمية.

إن غرس القيم الأخلاقية في نفوس الطلاب المراهقين ليس أمرا سهلا. أشارت البيانات إلى إلى

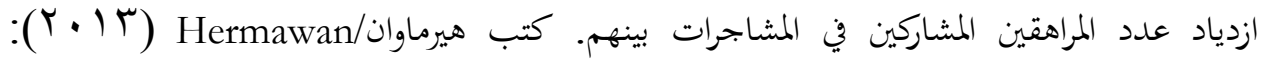

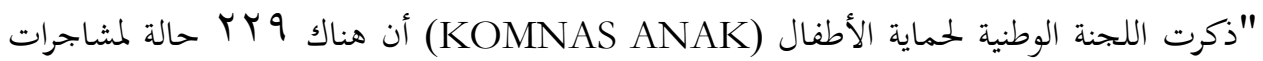

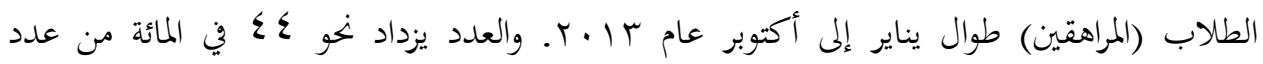

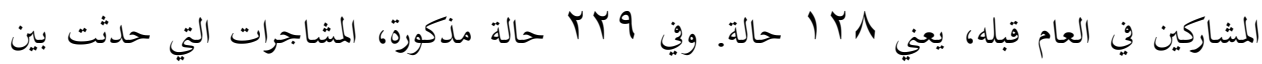
طلاب المدرسة المتوسطة والثانوية العامة قد قتل 19 تلميذا."

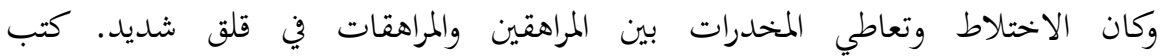

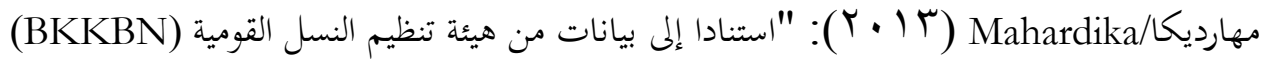

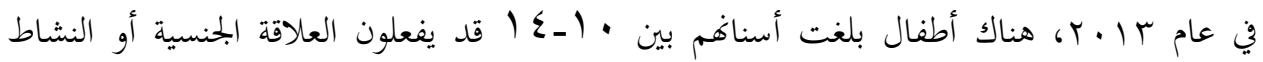

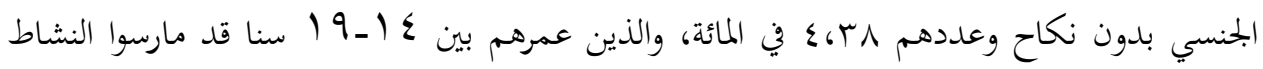

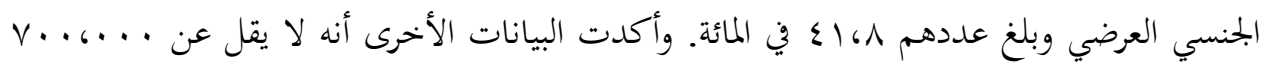

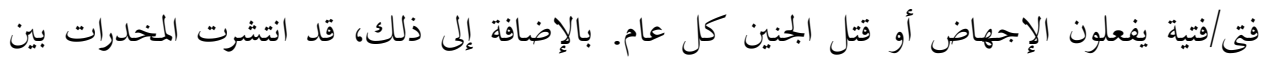

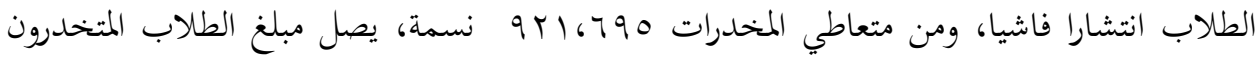

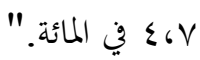




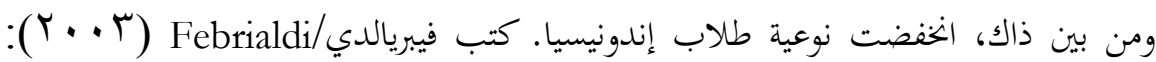

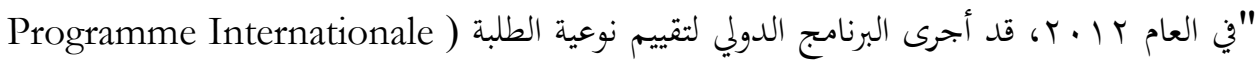
(for Student Assesment

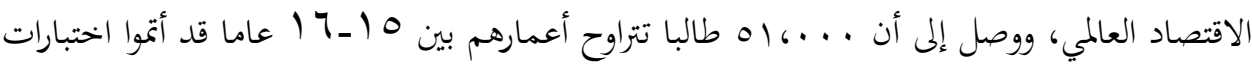

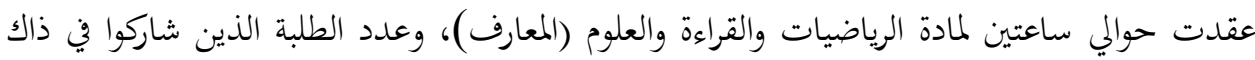

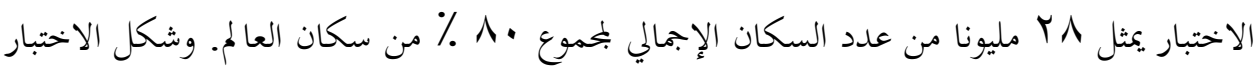
هو اختيار متعدد الأجوبة وتعبير المقال.

وشارك أيضا في هذا الاختبار مديرو المدارس لإجابة بعض الأسئلة عن خلفيات الطلاب

ومدارسهم، و عن مواقفهم في بيئة المدارس، والنظم المستخدمة في عملية التعليم. ونال طلاب

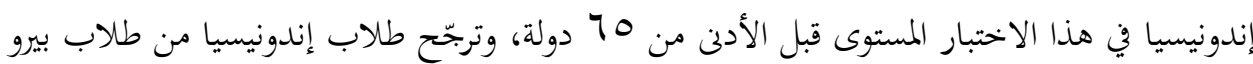
(Peru)

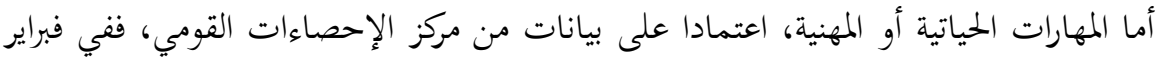

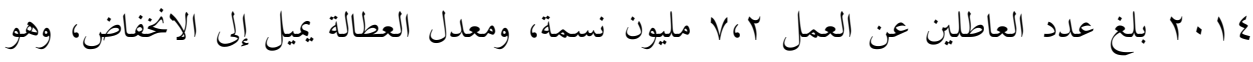

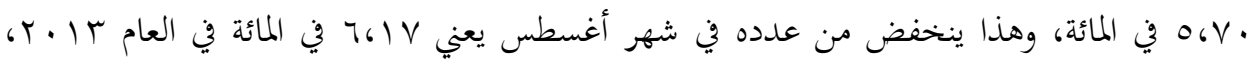

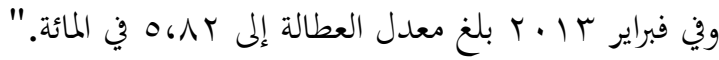

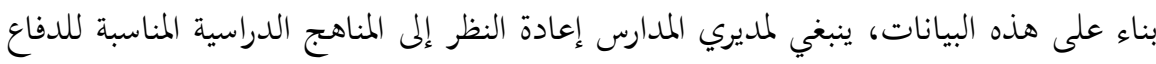

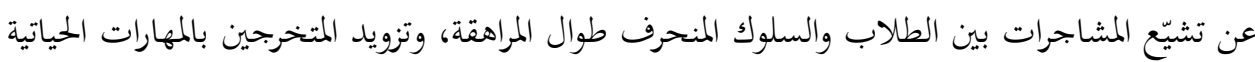

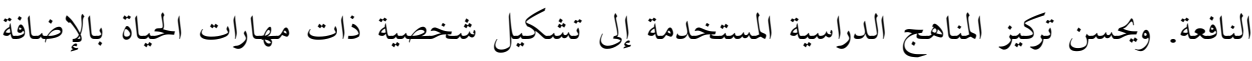

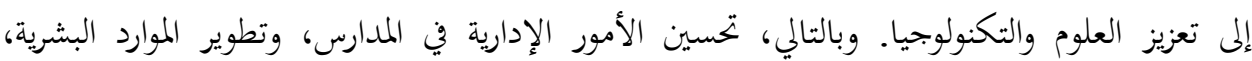
وتفعيل المرافق المدرسية.

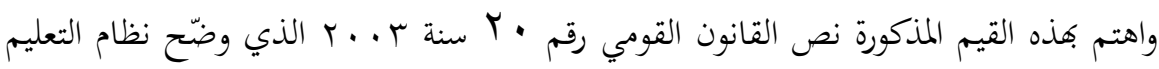

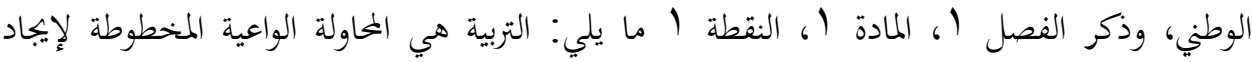

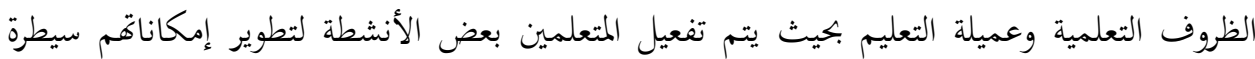

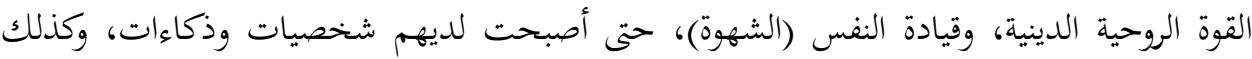

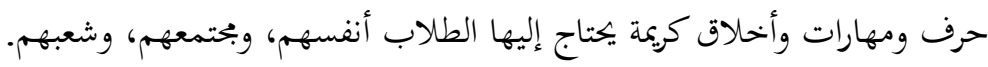


Jejen Musfah

فإجادة الإدارة لتنمية الثقافات المدرسية هي أول حلول للمشكلات المذكورة. وثقافة المدرسة يمكن تعلمها من الحقائق (المظاهر) التي تظهر في أشكال السلوك ورموز الخصائص الأخلاقية فيها. ومن المعروف، أن للمدارس الدينية ميزات في تشكيل شخصية الطلاب، وأفم يبتعدون عن المشاجرة بينهم. بالإضافة إلى التميز الأخلاقي، اهتمت المدارس الدينية بتطوير العلوم والاختصاصات المهنية تزويدا لمستقبل الطلاب.

والغرض من هذا البحث هو تحليل عمليات التميز أو التفوق للمدرسة المتوسطة الدينية الأولى يوجياكارتا، وهي التميز الأخلاقي، والتميز العلمي، والتميز المهني. استخدم الباحث المنهج الكيفي عن طريق أسلوب التحليل الوصفي. وقد تم جمع البيانات باستخدام الملاحظة المباشرة، والمقابلات الشخصية المتعمقة، وتحليل الوثائق المتعلقة بالبحث. ويشمل أسلوب تحليل البيانات تخفيض البيانات وعرضها والاستنتاج بها. وتحقيق صحة البيانات يتم عن طريق تمديد الباحث في المدرسة ملاحظا الحالات الواقعة، والمراقبة المكملة الدقيقة، وتقنية التثليث باستخدام بحموعة المصادر والطرق والنظريات

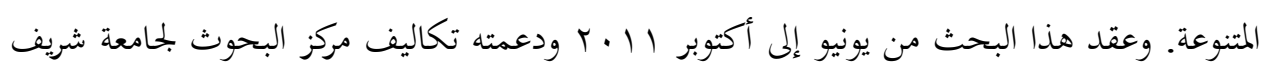
هداية الله الإسلامية بجاكرتا.

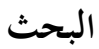

\section{الرؤية والرسالة}

المدرسة الثانوية الدينية الحكومية الواحدة (MAN I) يوجياكارتا تقع جغرافيا في المنطقة الشمالية من مدينة يوجياكارتا، وحوالي · · ( مترا شمالا، وهي دخلت إلى إقليم سليمان (Sleman). هذا الموقع يصلح لعملية التعليم والتعلم لأنه قريب من المراكز الشهيرة للتعليم العالي في إندونيسيا مثل جامعة غاجاه مادا (UGM))، وجامعة إندونيسيا الإسلامية (UII)، وجامعة يوجياكارتا الحكومية (UNY) (Gondukusuman) (G) وبجانب المدرسة في نفس منطقة جوندوكوسومان أيضا المدرسة الثانوية الحكومية والمدارس الثانوية الأهلية، وبعض المدارس الأهلية ومحلات التعلم الإضافي، والمكتبات، وما يحتاج إليه الطلاب في التعلم من أدوات مدرسية أوتصوير ورقات يمكن للطاب أن يرقوا

$$
\text { إبجازهم في الدراسة. }
$$

ومع تنمية المناطق الحضارية إلى الشمال، يعنى شارع كاليؤورانج (Kaliurang)، حدثت بعض التغييرات المدنية، وخاصة تسهيل مسار نقل للوصول إلى المدرسة من مختلف الأنواع ومسارات النقل، وتنمو كذلك المحلات التجارية نموا سريعا. 
من ناحية الموقع الجغرافي، يمكن وصف المدرسة على النحو التالي: الجحانب الشمالي يحدّها شارع

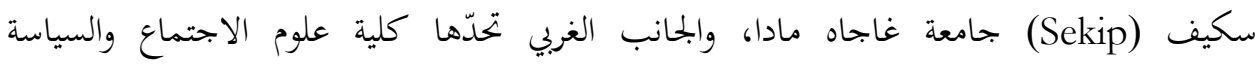
(FISIPOL) الشرقي يحدها شارع تش. سيمانخونتاك (C. Simanjuntak).

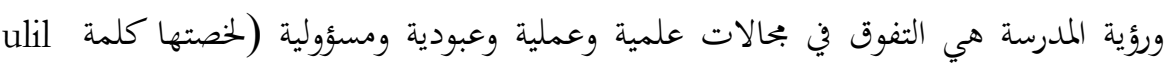

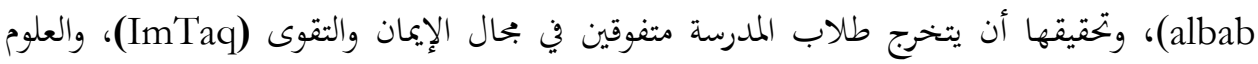

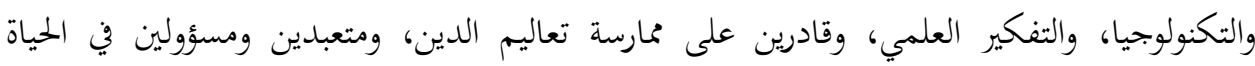

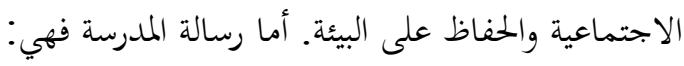
' ا غرس الإيمان والتقوى والعبادة والأخلاق الفاضلة وترقيتها حتى أصبح أسلوبا للحياة.

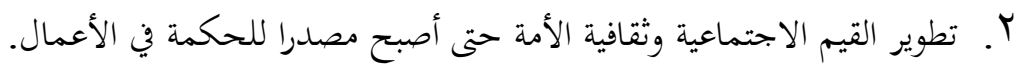

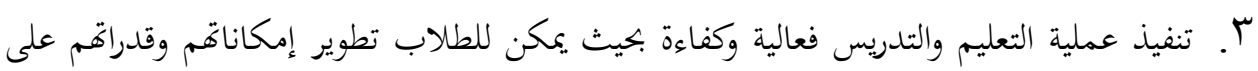
النحو الأمثل.

ع. تحسين تعليم الطلاب من خلال التعليم الأخلاقي المتفوق والمثتقف والفعال والمبتكر والمتمتع أو المثي. المثير. ○. إنشاء روح المنافسة أوالمحاهدة للطلاب في المحالات الأكاديمية وغير الأكاديمية. T. إعداد الطلاب وتيسيرهم إلى إكمال الدراسات الجحامعية. V. تنمية الشعور بالمسؤولية في حياة المختمع والحفاظ على البيئة.

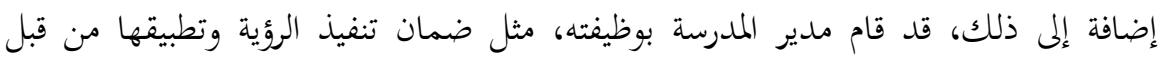

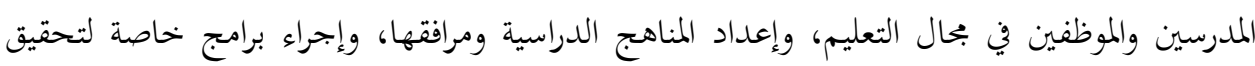

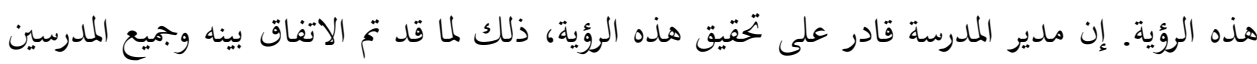
والهيئة التعليمية، ويلزم على كل من يتفق بها تحقيقها.

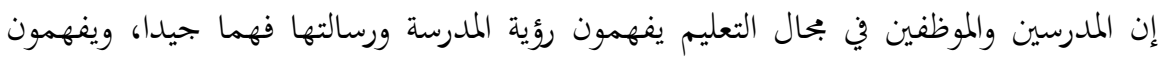

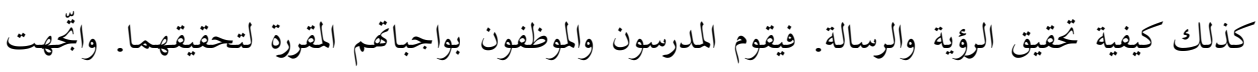

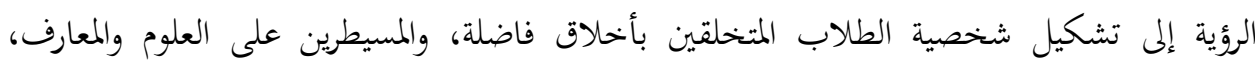

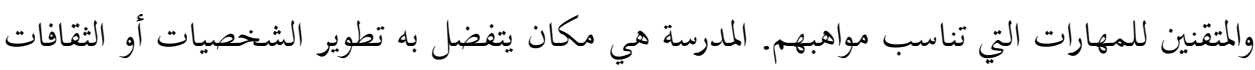
(الإنسانية) والمعارف والمهارات النافعة للطلاب ناتحة من تنفيذ المناهج الدراسية تنفيذا موافقا ومكملا. 
Jejen Musfah

وأهداف التربية والتعليم إيجاد الطلاب الماهرين في العلوم والمهارات الحياتية. يكشف جارفيس

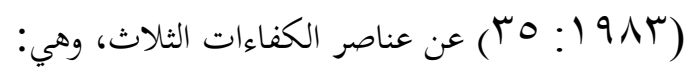
أ. المعرفة والفهم، بما فيهما التخصصات الأكاديمية، والعناصر النفسية، والعلاقات الشخصية الثعية، والقيم الأخحلاقية.

ب. المهارات، بما فيها تنفيذ إجراءات العوامل النفسية وكذا التفاعل مع الآخرين؛

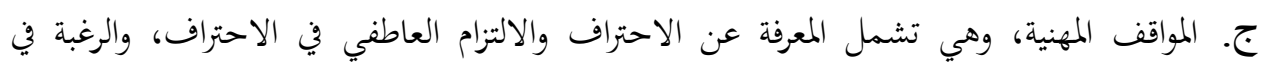
العمل بطريقة مهنية.

وأكدت اليونسكو (ديلور/Delor، 99 V 1 ) إلى أهمية المراكز الأربعة التي يجب القيام بها في

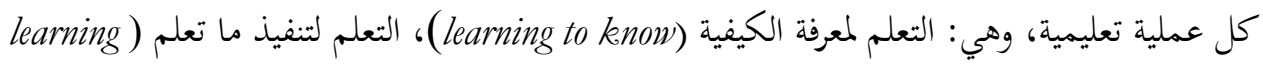

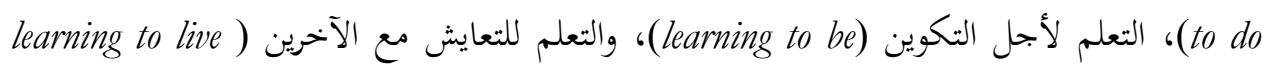
.(together

إذن، دلت رؤية المدرسة ورسالتها على ابحاه تطوير شخصية وأخلاق الطلاب بتزويد العلوم

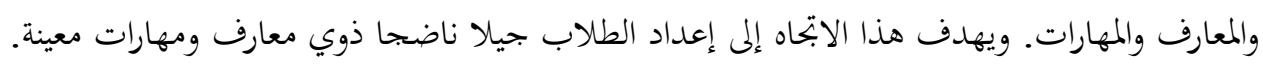

\section{التميز في الشخصية}

لقد أجرى مشتركو الندوة لجامعة هارفارد (Harvard) بحثا مسحيا عن رغبات المواطنين

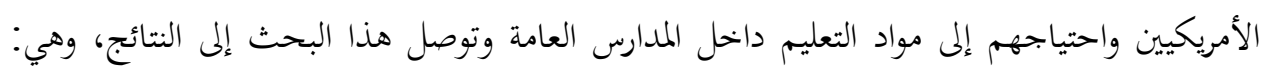

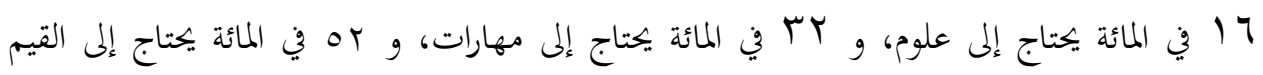

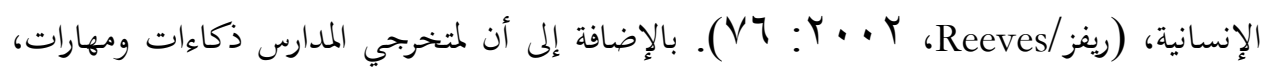
يجب لديهم أخلاق فاضلة.

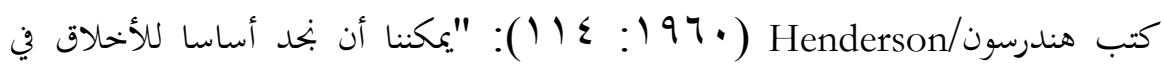

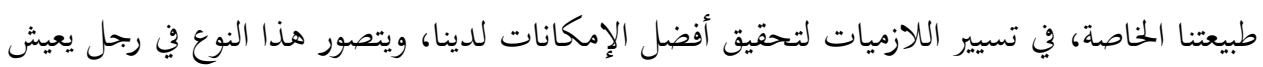

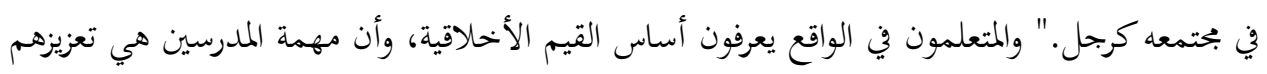

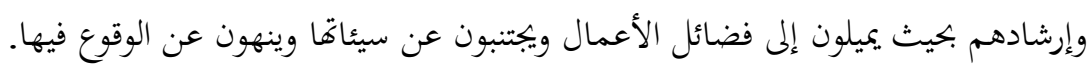

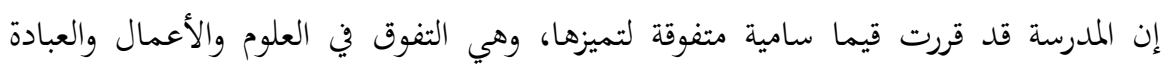
والمسؤولية (لخصتها كلمة ulil albab). وقامت المدرسة بتشكيل الشخصية والأخلاقية أو الثقافية من فئن 
خلال تنفيذ المناهج الدراسية وتعويد السلوك الفاضل من أنشطة روتينية أو عفوية، وعن طريق النماذج والأنشطة المبربجة.

استخدمت هذه المدرسة المناهج الدراسية المناسبة لمستويات المدارس التي قررةا الحكومة عام

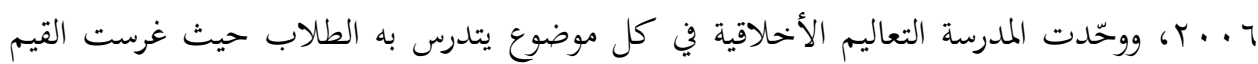

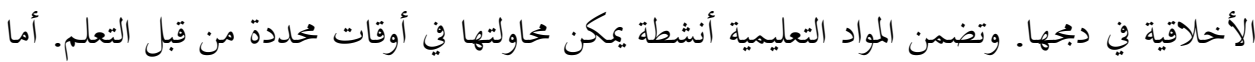

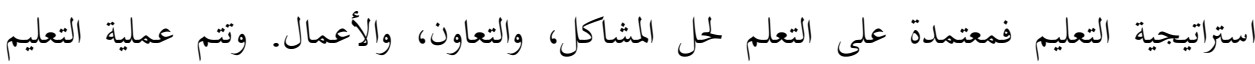

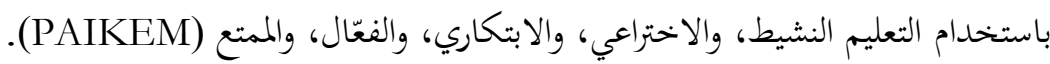

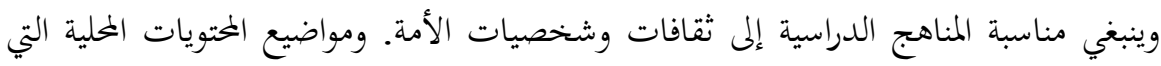

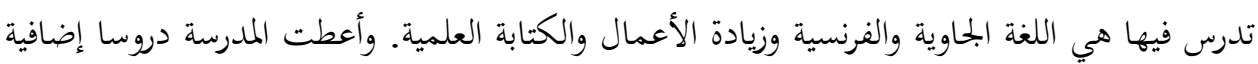

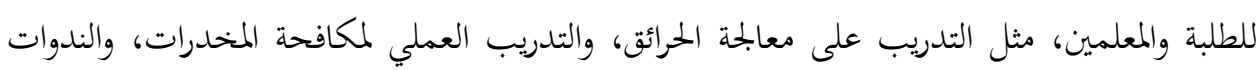

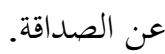

ومن واجبات مطوري المناهج الدراسية الاهتمام بالجوانب الأخلاقية، كما كتبه جون د ـ ـ المان.

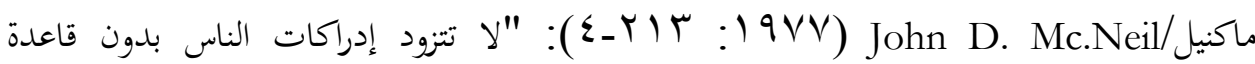
أخلاقية، لا بمناهج الحكومة، أو مداخل تكنولوجية أو تقاريب مادية، فمراجعة هذه القضايا لن تكفي

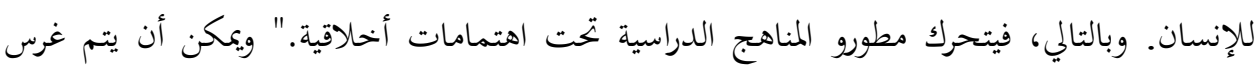

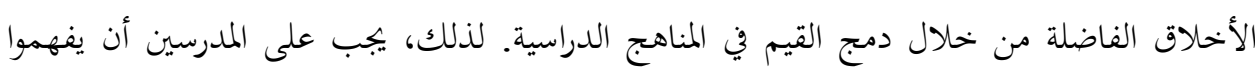

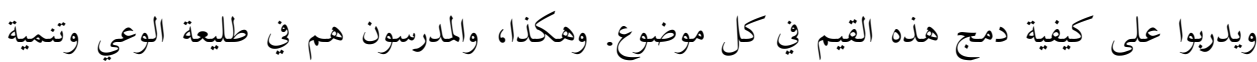
القيمة.

وتزودت المدرسة بمنازل خاصة للطلاب المتخصصين في قسم العلوم الدينية. ويتدرب الطلاب فيها تدريبا مكثفا لسيطرة المواد الدينية والتميزات الشخصية على أساس الدين.

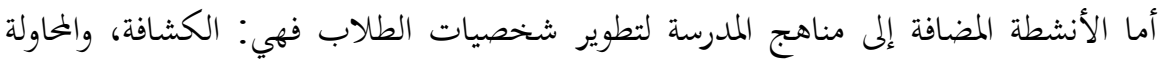

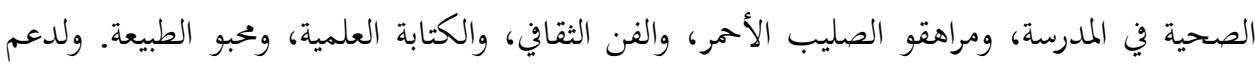

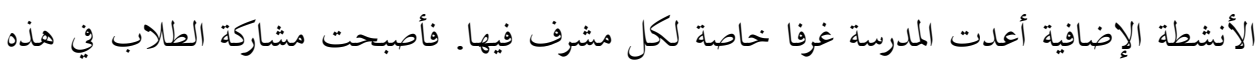

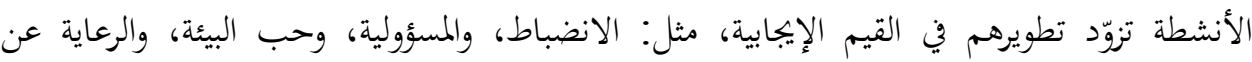
الآخرين. 
Jejen Musfah

إضافة إلى ذلك، للمدرسة أيضا أنشطة عادية مثل اعتصام الفصول، وصلاة الظهر جماعة، والمحاضرات القصيرة؛ وأنشطة عفوية مثل الامتنان، ووضع القمامة في مكاها، وطلب المغفرة؛ وأنشطة نموذجية مثل الإخلاص والالتزام والانضباط؛ وأنشطة مبربحة مثل حفل العلم، وقراءة القرآن وكتابته، والسباق في النظافة. وهذه الأنشطة التي اشتركها الطلاب ومعلمو المدرسة تدعم تكوين شخصية/الثقافة، سواء في الفصول الدراسية وخارج الفصول الدراسية. وكان في المدرسة مسجد له طابقان لصلاة الجماعة. ونالت المدرسة الفائز الأول الوطني لمسابقة النظافة، وهذا يدل على شخصية نظيفة ومحبة البيئة.

كتب كوتر/Kotter و و هيسكيت/Heskett الصفات من أي مجموعة بشرية التي تسير من جيل إلى جيل". ويحدد دايل/Deal وبيترسون/Peterson ( •99 19 (: ع) ثقافة المدرسة بأفا "أنماط عميقة من القيم والمعتقدات والتقاليد التي يتم تشكيلها على محاولات المدرسة الطويلة." وتقافة المدرسة هي المعارف ونتائج الأعمال من المحتمع المدرسي الذين يحاولون على تحويلها إلى الطلاب، وتستخدم هذه الثقافة كدليل في كل أعمال البحتمع المدرسي. وتتمثل المعارف في المواقف والسلوك من بحتمع المدرسة حتى تظهر ألوان الحياة المدرسية التي يمكن جعلها مرآة لأي شخص تشارك فيها.

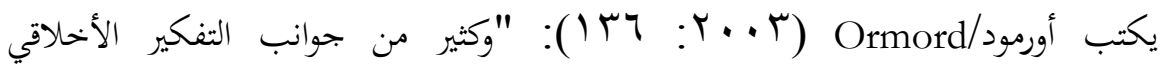
وسلوكياته تتأثر على ما يبدو من خلال المراقبة والنموذج." النموذج أو القدوة لا تكفي بالبيان فقط، لكن يجب أن تتجلى في سلوك مديري المدارس والمعلمين والمربين. إن الطلاب سيعيشون في المحتمع بعد إتمام الدراسة. لذا، يحتاج المدرسون إلى توضيح القضايا الاجتماعية والأخلاقية، حتى عواقب الأفعال السياسية (بينار، ؟ • • ب: 7 1). ويدرك المدرسون أن

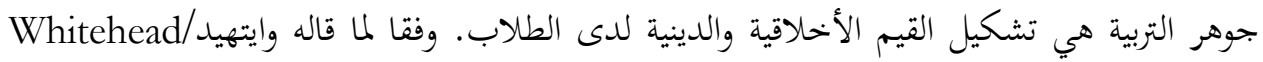
"190V) في كثير من الأحيان، لم تتحقق القيم التربوية الأخلاقية من قبل المعلمين، بالرغم أفهم يقومون

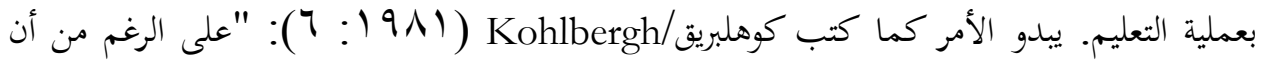
المعلمين يدرّسون القيم الأخلاقية، لكنهم لا يدركون جوهرها. وهم يقولون للأطفال ما يجب القيام به،

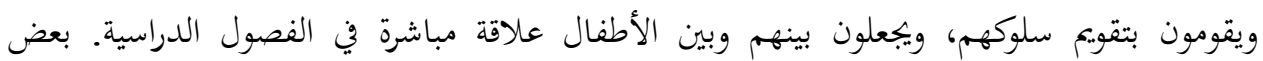


المعلمين يفعل هذه الأشياء مرات دون أن يدرك أها من جواهر القيم التربوية الأخلاقية، ولكن الأطفال

يدركونها."

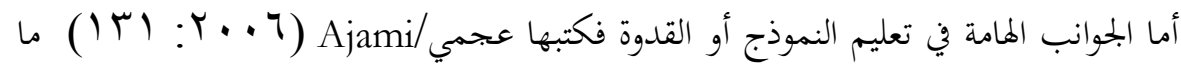

أ. إن الإنسان مادام متفاعلا مع غيره من خلال الأقوال، والأعمال، والأفكار، والمعتقدات. ب. إن الأفعال أكثر أثرا من الأقوال. ج. الطريقة المثالية لا تحتاج إلى تفسيرها.

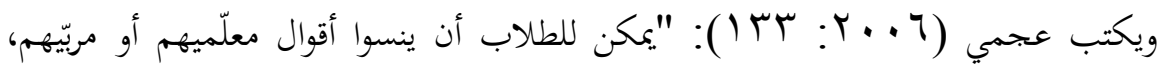

لكنهم يتذكرون أبدا مواقفهم وسلوكهم." يجب على المدارس، إذن، غرس القيم الفاضلة لدى تلاميذها في أوقات مبكرة، حتى يقدروا

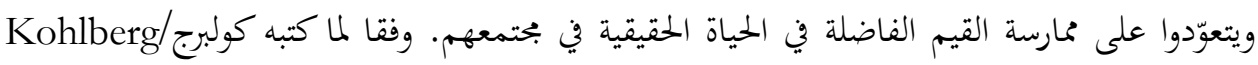

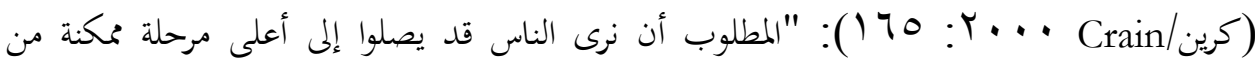

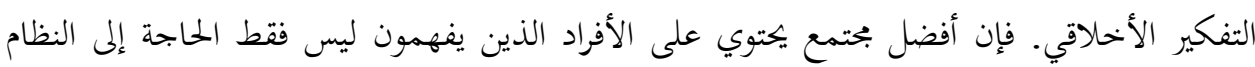

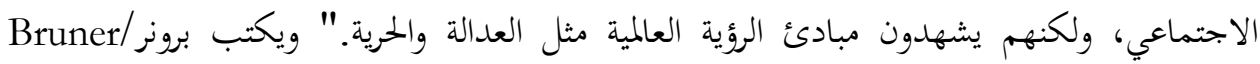

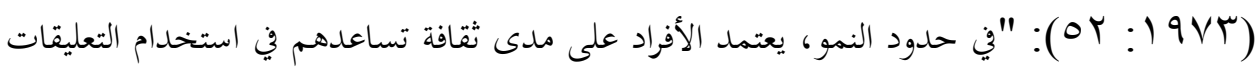
الفكرية المختملة." وينبغي للمدارس من خلال البرامج المدرسية وأنشطتها أن يعلّموا الطلاب القيم الفاضلة ليعرفوا

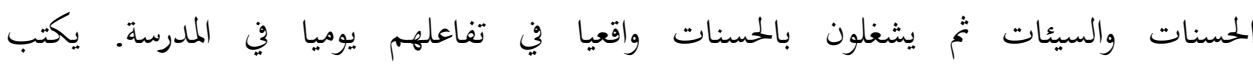

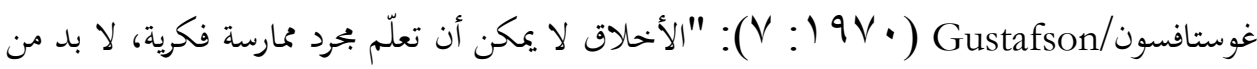

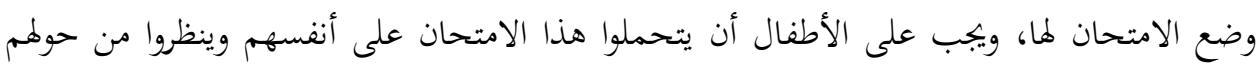

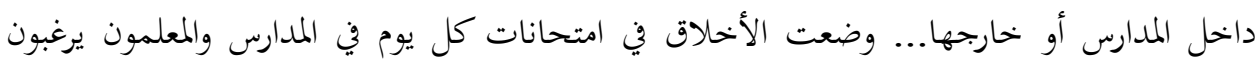

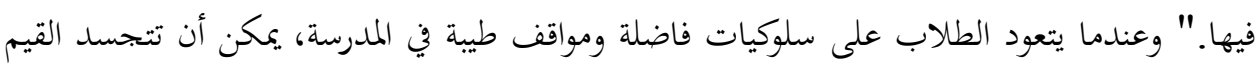

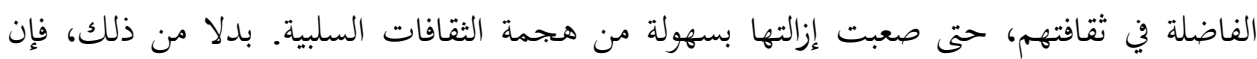

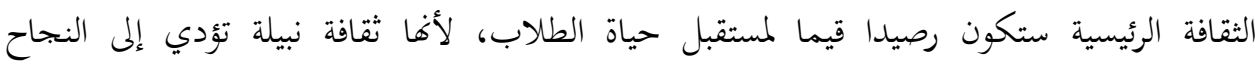


Jejen Musfah

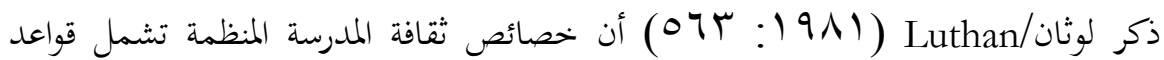

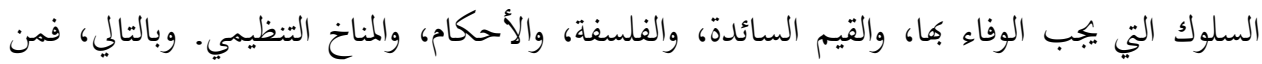

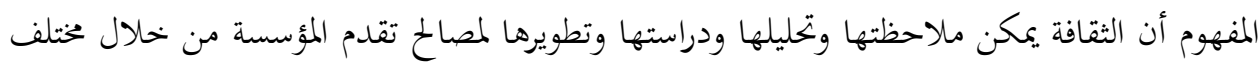
مظاهر الثقافة والعناصر الواردة فيها. ويذكر كالدويل/Caldwell وسبينك/Spink (ب (99 19: 99 (7) بعض عناصر الثقافة التنظيمية للمدرسة على النحو التالي: تجسيد المفاهيم/الألفاظ، بتسيد الرموز/ المواد البصرية وتعبيرها، والمظاهر

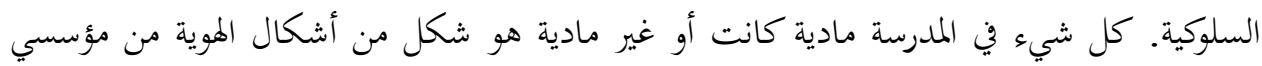

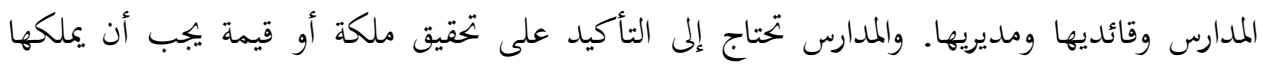
الطلاب بعد دراسة لمدة ستة أو ثلاثة أعوام. وبهذه الطريقة يمكن قياس فعالية المدرسة.

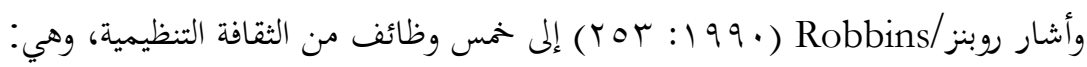

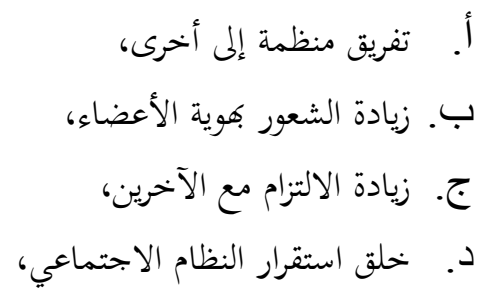
ه. آلية المكافحة المتكاملة وتشكيل مواقف وسلوك الموظفين.

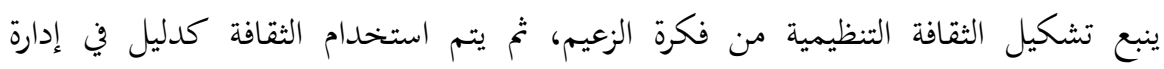

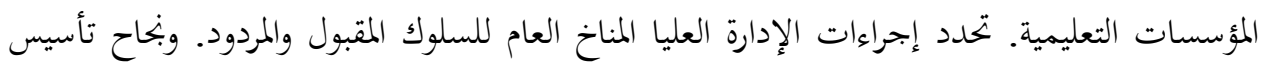
الثقافة في المدرسة يعتمد على التركيز والالتزام من القادة.

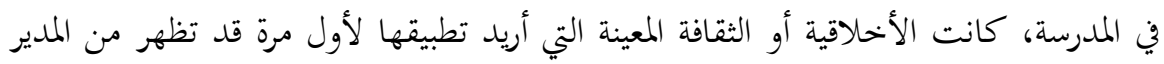

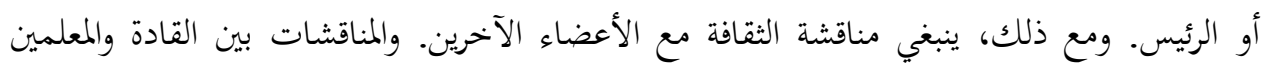

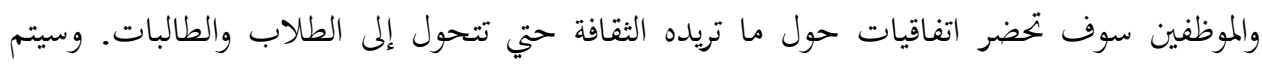

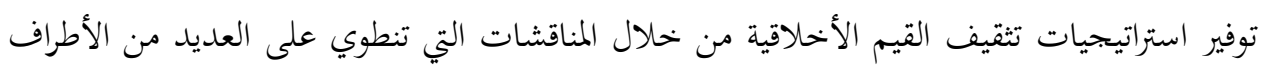

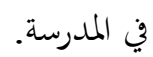

إضافة إلى ذلك، يتعين على المدارس إعداد إجراءات التقييم في تنفيذ الثقافة. فنجاح غرس

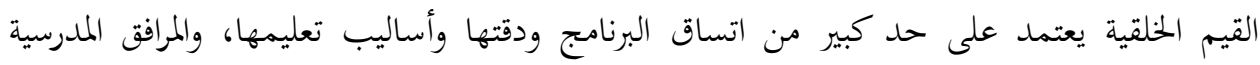
الداعمة لها، وقدوات يقتدى بها مديرو المدارس، والمعلمون، والموظفون. 


\section{التميز في العلوم والمعارف}

يعيّن المجتمع المدرسي إلى أن المدرسة يجب أن تتميز بالعلوم والتكنولوجيا. لذا، يدرس فيها

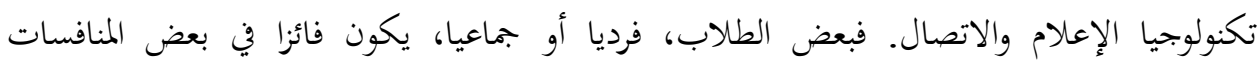

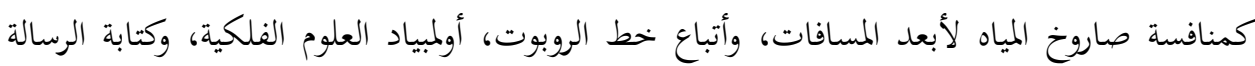
العلمية في علوم الطبيعة.

بمناسبة هذه التميزات، بذلت المدرسة جهودها خاصة لمواجهة الامتحان الوطني، والامتحان

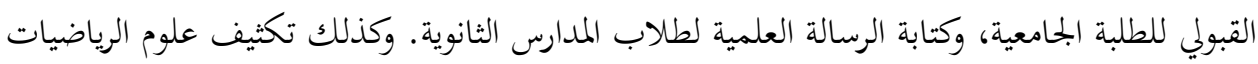
والفيزياء والكيمياء لطلاب قسم العلوم الطبيعية.

ومدرسو العلوم والمعارف في هذه المدرسة قد تميزوا بقدراقم وخبراقم، وهم متخرجو الجامعات المعات

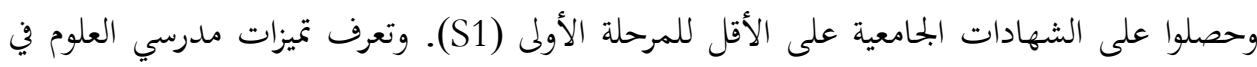

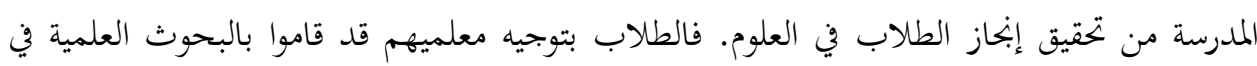
العلوم والمعارف.

فالتفوق العلمي في المدرسة يعرف أيضا من عدد المتخرجين الذين قبلوا في الجامعات الحكومية.

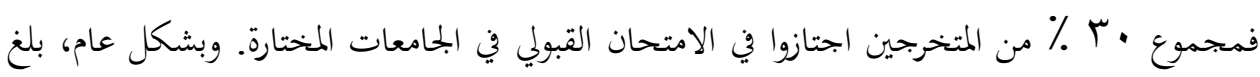

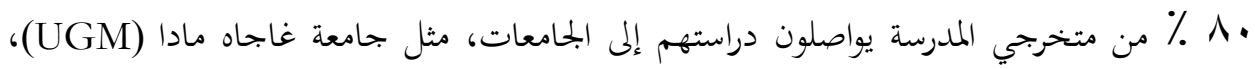

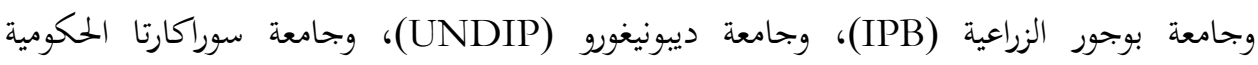

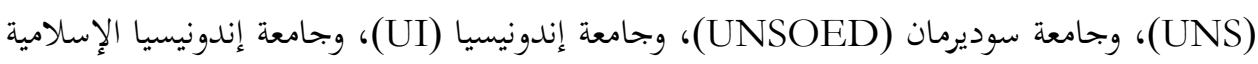
(UII)، وجامعة يوجياكارتا الحكومية (UNY)، والجامعات الإسلامية الحكومية، وجامعة الأزهر

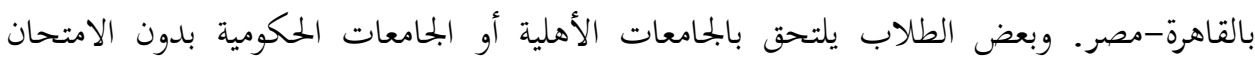

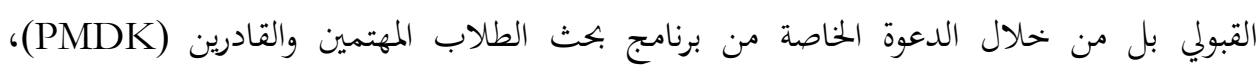

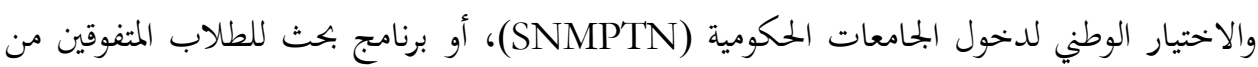

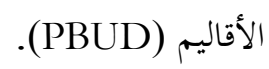

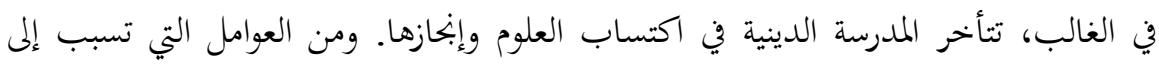

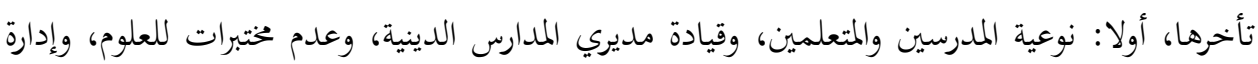

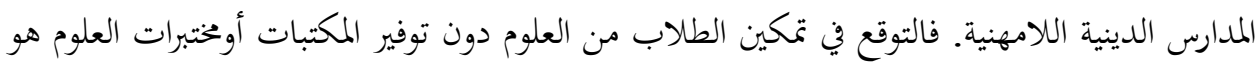


Jejen Musfah

أمر مستحيل. لذا، اهتمت المدارس المتفوقة اهتماما كبيرا لإكمال الوسائل التعليمية الوافرة في العلوم الطبيعية. قال غاردنر/Cowell/Gardner/ وكويل (990 1: 0 هץ): "ويقصد بمصادر التعلم، منها: معدات التدريس يستخدمها المعلمون في تدريسهم. و تعني المعدات جميع السلع التي يمكن استخدامها في المدارس لمساعدة المدرسين على عملية التعليم." لذا، تنوعت المعدات أو اللوازم المدرسية مثل الكرة الأرضية، والخرائط، والرسوم البيانية، والرسومات، والنماذج، وبحموعة الأدوات أو وسائل الدراسة. وكذلك الكتب، مدرسية كانت أو مكتبية، ومختبرات الفيزياء والكيمياء والبيولوجيا الكافية والمريحة. وعدد المعدات أو اللوازم المدرسية في المدرسة لا يدل على صلاحية المدرسة وإبحازاتا. وتعتبر المدرسة فاسدة بكثرة معداتحا المدرسية إذا لم توفر استخدام المعدات على الإطلاق. وأكد

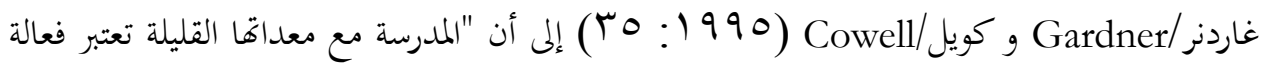
إذا استخدم المعلمون والطلاب المعدات بطريقة فعالة حتى تساعد التلاميذ على فهم الدروس بشكل أفضل. وهذا يدل على أهمية إدارة المدرسة لتسهيل المعلمين بدورة تدريبية قصيرة حول كيفية استخدام الوسائل والمرافق التعليمية بما فيها المعدات واللوازم المدرسية بفعالة وكفاءة. وهكذا، يمكن للمعلمين استفادة الوسائل والمرافق المدرسية والمعدات المتاحة في المدرسة على أفضل طريقة. أما المرافق المدرسية الأساسية التي يجب أن تتحقق في المرحلة الابتدائية فهي الفصول الدراسية، وغرف المعلمين، والمكتبة، والمحاولة الصحية في المدرسة، ودور العبادة، والمراحيض، والرياضة، و معمل العلوم الفيزيائية. والمرافق المدرسية الأساسية في المدارس المتوسطة هي المرافق الأساسية في المرحلة الابتدائية، وبالتالي المشورة والمنظمات الطلابية والإدارة. وفي مستوى المدارس الثانوية، يجب استكمال البناءات الأساسية للمختبرات، مثل مختبر علوم الفيزياء ومختبر علوم الكيمياء ومختبر علوم الطبيعة، ومعمل

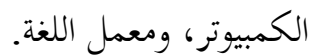

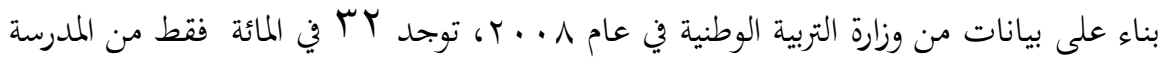
الابتدائية التي تملك مكتبة، بينما في المرحلة المتوسطة س،با في المائة. أما في مستوى المدارس الثانوية توجد مكتبة المدرسة الثانوية الحكومية حيث بلغ • ^ في المائة وبلغ • 7 في المائة في المدرسة الثانوية الخاصة، وبلغ في المدرسة الثانوية للتدريب المهني (SMK) • 9 في المائة. وفي المدرسة الثانوية العامة 
التي لها مختبر الوسائط المتعددة • 1 في المائة، في حين أن ـ0 في المائة من المدارس الأهلية.

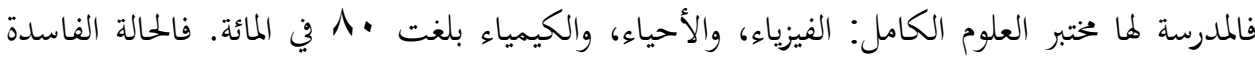
تحدث في المدرسة الأهلية لأنه لا يملك مختبرات العلوم الفيزيائية الثلاثة إلا • ( في المائة، و •ـr في المائة

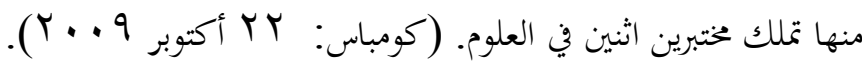

\section{التميز في المهارات الحياتية (المهنية)}

لا يستطيع جميع متخرجي المدرسة أن يواصلوا دراستهم إلى الجامعات. وترجو المدرسة لمن تخرج ألماته

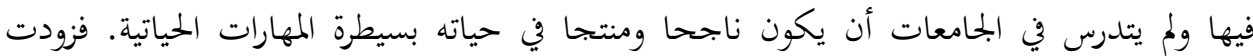
المدرسة متخرجيها بالتدريبات المهنية والتخصصات النافعة.

فالمناهج المهنية التابعة داخل مناهج المدرسة هي: أولا، اللغة الفرنسية، وكتابة الرسالة العلمية، وتدريب الخطبة والمحاضرة التي تخصّ لطلاب قسم اللغة (في الفصل العاشر). وثانيا، الإلكترونيات تخصّ الفّل

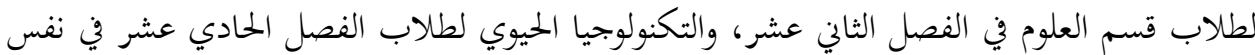

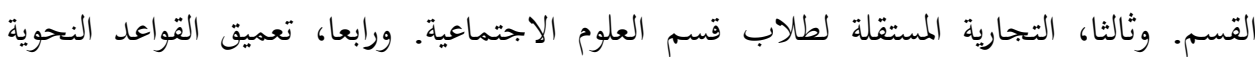
والصرفية لطلاب قسم الدين. والمناهج المهنية التابعة خارج مناهج المدرسة هي الرسالة العلمية للطلاب، وتدريب الخطبة والمحاضرة، وشرح آي القرآن، والموسيقى، والرياضة (كرة السلة، والفوتسال، وكرة

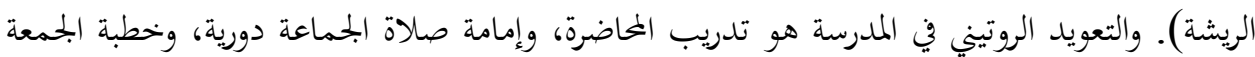

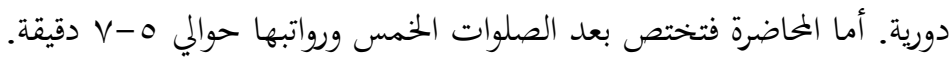

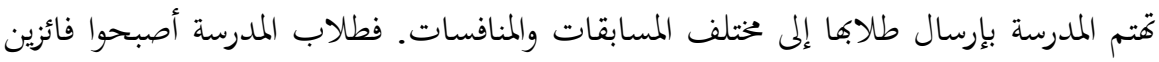

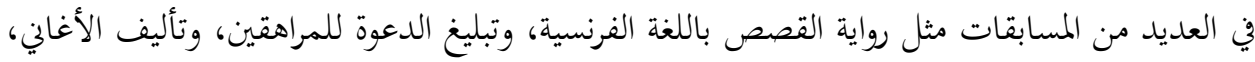

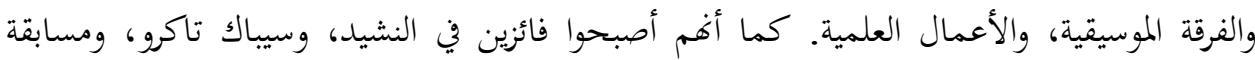
تلاوة القرآن البموّدة، والخطا، وفهم معاني القرآن، والموسيقى الدينية، وكرة الريشة، وكرة الطاولة، والكرة الطائرة.

يجب أن يكون متخرجوا المدرسة جيلا قويا متينا في عقوهم، وذلك للردّ على أي مشاكل تره

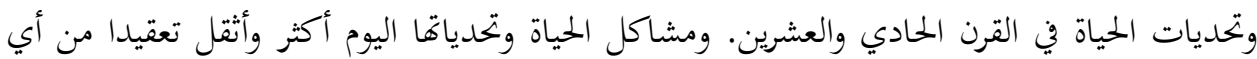

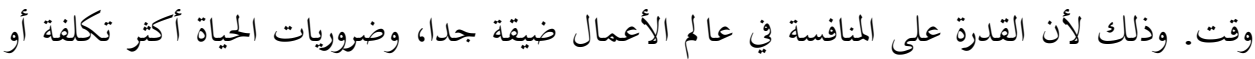
ثمينة، وتتطلب القوة الذهنية وقدرة الخلاقة. وإذا لم يتزود الطلاب بالمهارات الحياتية، من خلال 
Jejen Musfah

التدريبات والخبرات داخل المدرسة، فيمكن أن يصبحوا عاطلين عن الأعمال وبالتالي أن يكونوا أثقالا لمتمجمع.

لإعداد المتخرجين الماهرين والمستقلين، سعت المدرسة توفير تنفيذ التخصصات في المناهج المهنية

التابعة داخل المناهج وخارجها التي يمكن تزويد الطلاب مهارات محددة، وخاصة لمن لا تستطيع في مواصلة التعليم العالي.

ولمتخرجي المدرسة كان تمكين المهارات المهنية رؤوس أموال ضخمة لتطوير إمكاناقم وقدراتم كمستقلين في الأعمال، إما أن يكون عاملا أو رجلا زراعيا مستقلا.

وبجانب الذكاء الفكري، تربى المدرسة طلابها الذكاء العاطفي، بما فيه المهارات الصعبة والمهارات

الناعمة. والمهارات الحياتية تحتوي أيضا مواجهة حالات السعادة والحزن في المعاش، وتوفر الراحة

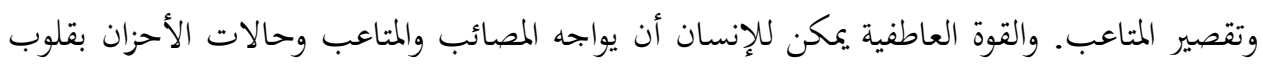

مطمئنة.

يجتاج الطلاب إلى المهارات الحياتية في وقت مبكر. وعرفت منظمة الصحة العالمية المهارات الحياتية أفا قدرات تساعدنا على التكيف والتصرف بشكل إيجابي بكيث يمكن التعامل مع تحديات

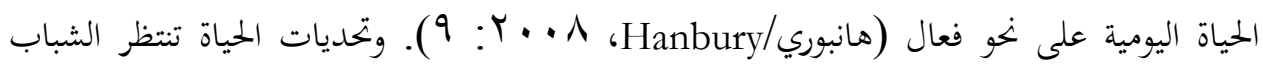
وتتطلب جهدا واعيا من الآباء والأمهات والمدارس والمحتمعات المحلية لإكسابهم المهارات الحياتية في أقرب وقت ممكن.

هناك خمسة بحالات أساسية للمهارات الحياتية المناسبة للتطبيق في أي ثقافة (قسم الصحة النفسية لمنظمة الصحة العالمية، 999 19: (1)، وهي:

$$
\begin{aligned}
& \text { ! . . صنع القرار وحل المشكلة؛ } \\
& \text { r. التفكير الإبداعي والتفكير الناقد؛ } \\
& \text { ؟ ع. مهارات التواصل والتعامل مع الآخرين؛ } \\
& \text { ؛. الوعي الذاتي والتعاطف؛ } \\
& \text { ○. التعامل مع العاطفة والتعامل مع الإجهاد. }
\end{aligned}
$$

وبالنسبة إلى خمسة الجوانب المذكورة، فقدرات بحتمعنا الإندونيسي على صنع القرار وحل المشكلة تعتبر ضعيفة. قد نرى مشاكل الازدحام النقلي والفيضان على الشوارع، ولكن الحلول عنها غير متكاملة. والقرارات التي صنعها بحلس النواب الوطني والإقليمي لحل المشكلات لم تنفذ تنفيذا كاملا 
والمحتمع لم يتّبعها اتبّاعا خالصا. ونهن نرفض الفيضان ولكن تزدهر بناءات المراكز التجارية والمباني

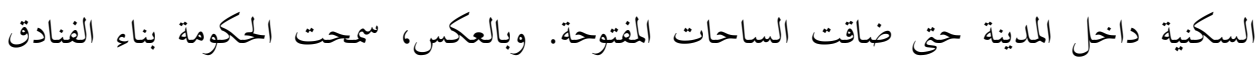

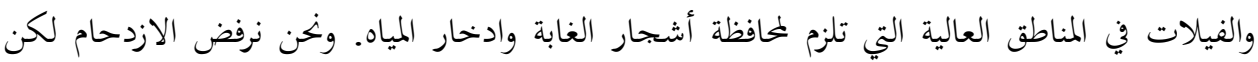
سُهّلت قروض السيارات الجديدة ويسمح نمو ملكية السيارات دون جهود السيطرة عليها.

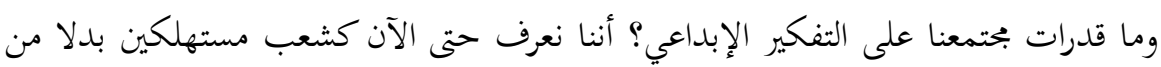

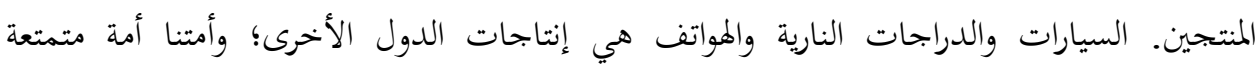

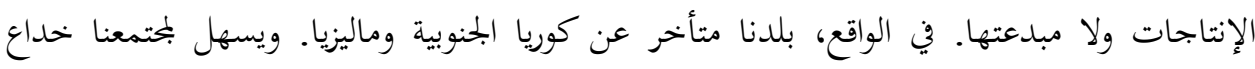

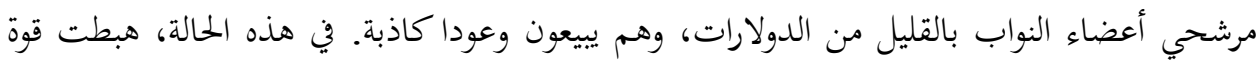
التفكير الناقد لدى بحتمعنا بسبب اختيار مرشحي النواب غير متكافئين ولامتنازهين.

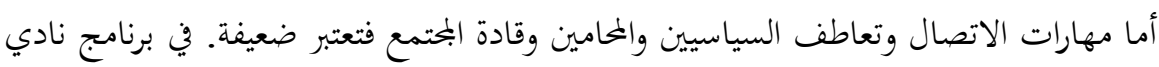

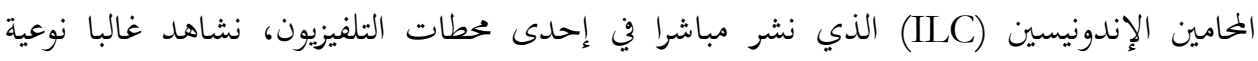

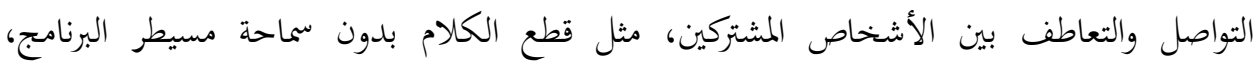
والتحدث بصوت عال مع عدم احترام آراء الآخرين.

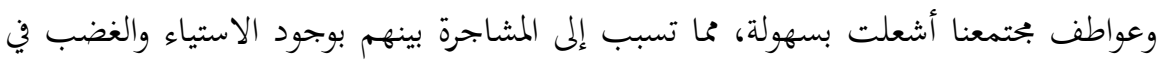

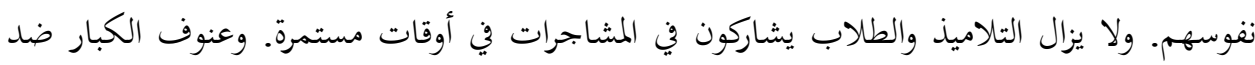

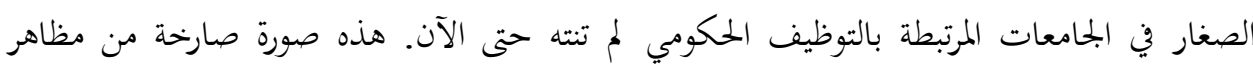

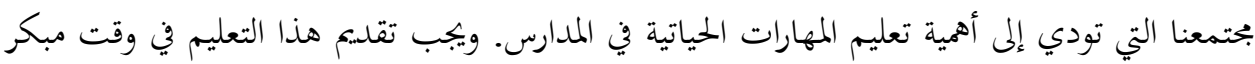

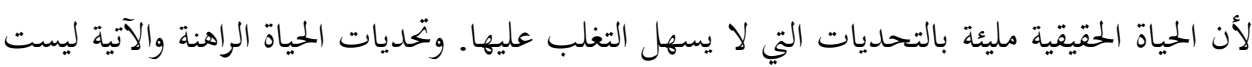

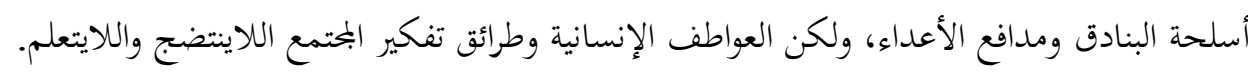

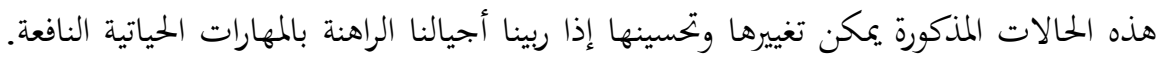

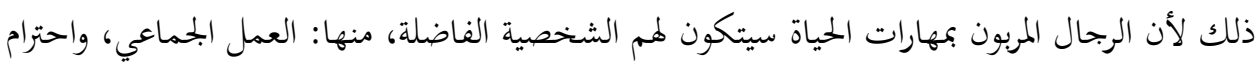

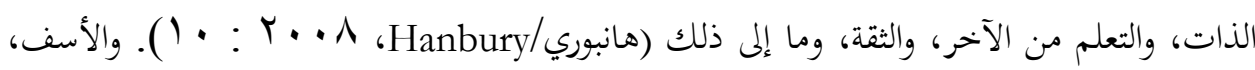

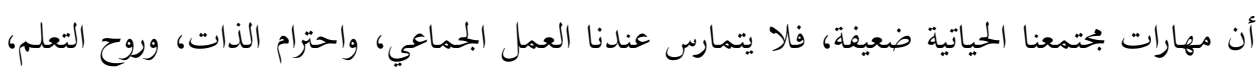
والثقة بالنفس.

ويجب على الحكومة أن تعمل مع البرلمان أو بحلس النواب لتطوير البلاد من أجل رفاهية الشعب. وبالعكس، لا ينبغي لها أن تعمل لمصالح الأحزاب الفائزة في الانتخابات العامة وشبكاتها. 
Jejen Musfah

وميزانيات الحكومة ونفقاتا لا تقسم إلى أعضاء الأحزاب الداعمة لما. وللأسف أن الرئيس قد يختار

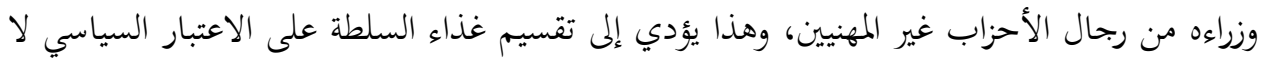
على أساس الاحتراف. أما السلطة فيرغب رجال الأحزاب أن يبذلوا كل جهد ممكن للحصول على المناصب المباف

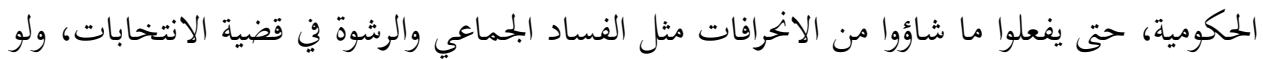

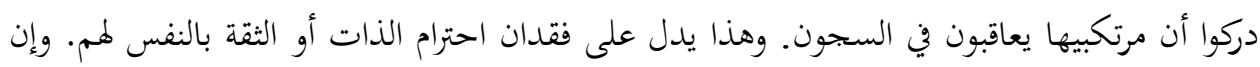

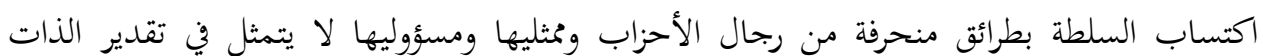
الشعبي.

ومن المعروف، أن بلدتنا الإندونيسية غنية بالموارد الطبيعية البرية والبحرية. ولكننا لم نتعلم

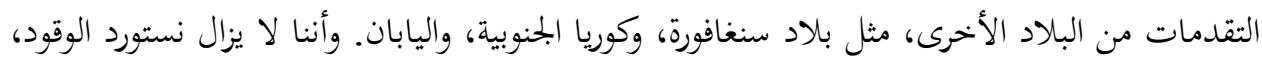

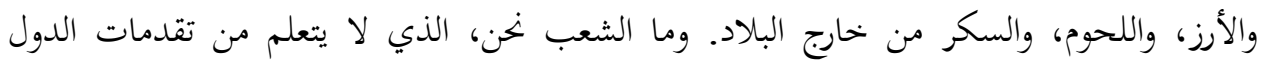

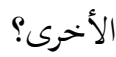

ومن المعروف أيضا، أن تلاميذنا ومدرسينا يمتلكون الثقة بالنفس المنخفضة. وفي عملية

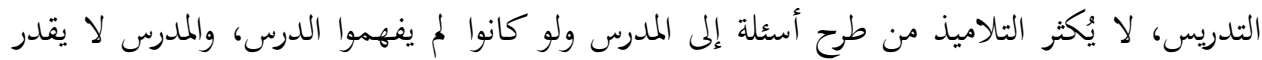

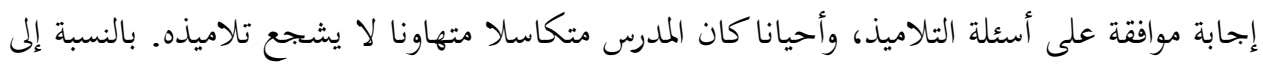

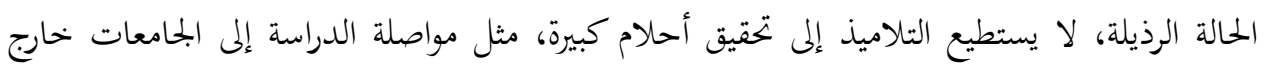
البلاد أو غيرها. والسؤال هو، لماذا فشل بجتمعنا في المهارات الحياتية؟ لأن المدارس تتشغل بتعليم العلوم فقط ولا تزود تلاميذها بالمهارات الحياتية، حتى لا تظهر محاولات تثقيفهم وتدريبهم وتربيتهم، ولا تغرس القيم

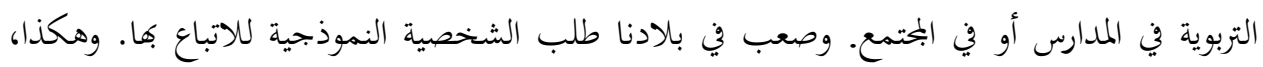

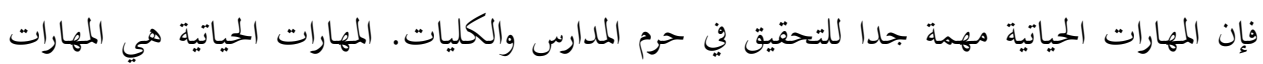
العامة ذات الصلة إلى العديد من التجارب المتنوعة في جميع مراحل الحياة (منظمة الصحة العالمية،

أظهرت نتائج البحث أن للمدرسة الثانوية الدينية الحكومية الواحدة (MAN I) يوجياكارتا

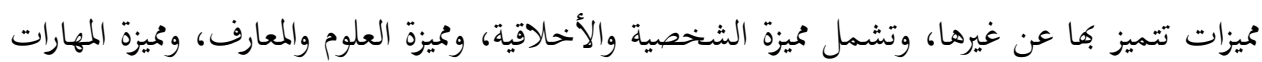


الحياتية أو المهنية. نجحت المدرسة في تحقيق رؤيتها بدعم وافر من مدير المدرسة، والمعلمين النزهاء، والموظفين الأكفاء، والمناهج الدراسية الممتازة، بالإضافة إلى المرافق التعلمية الكافية، والأنشطة المدرسية الفائقة. وجائزات المسابقات التي نالها الطلاب كل عام تظهر اهتمام مدير المدرسة والتزامه في تطوير الطلاب والمدرسين فيها.

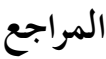
العجمي، م، ا. (T ؟). التربية الإسلامية: الأصول والتطبيقات، رياض: دار الناشر الدولي.

Bruner, J. S., (n.d.). The Relevance of Education. New York: The Norton Library. Caldwell, N. J. and Spink, J. M., (1993). Leading the Self-Managing School. London: Falmer Press.

Crain, W., (2000). Theories of Development; Concepts and Applications. New Jersey: Prentice Hall.

Department of Mental Health WHO., (1999). Mental Health Promotion; Partners in Life Skills Educaion. Geneva: World Health Organization.

Gardner, R., dan Cowell, N., (1995). Teknik Mengembangkan Guru dan Siswa; Buku Panduan untuk Penilik Sekolah Dasar. Jakarta: Grasindo. Penerjemah: Setyani D. Sjah.

Febrialdi., (2013, September 11, 2014). Siswa Indonesia Peringkat 64 Dari 65 Negara, tapi Paling Bahagia di Dunia. Retrived from http://edukasi.kompasiana.com.

Gustafson, J. M., et. al., (1975). Moral Education; Five Lectures. Cambridge and London: Harvard University Press.

Hanbury, C., (2008, May 2014). The Life Skills Handbook; An Active Learning Handbook for Working with Children and Young People. Retrived from www.lifeskillshandbooks.com.

Hermawan, E., (2013, September 11, 2014). Tawuran Sekolah Jakarta Naik 44 Persen. Retrived from http://www.tempo.co.

Jarvis, P., (1983). Professional Educati

on. London-Canberra: Crown Helm.

Kohlberg, L., (1981). The Philosophy of Moral Development. San Francisco: Harper \& Row

Kotter, J. P., and Heskett, J. L., (1992). Corporate Culture and Performance. New York: The Free Press.

Luthan, F., (1981). Introduction to Management. New York: McGraw-Hill Book Co.

Mahardika, M. F., (2013, September 11, 2014) Relfleksi Pelajar Akhir Tahun Pelajaran 2012-2013. Retrived from http://edukasi.kompasiana.com. 
Jejen Musfah

McNeil, J. D., (1977). Curriculum: A Comprehensive Introduction. Canada: Little, Brown \& Company.

Ormrod, J.E., (2003). Human Learning. Fourth Edition. New York: Pearson Prentice Hall.

Pinar, W. F., (2004). What Is Curriculum Theory? New Jersey: Lawrence Erlbaum Associates

Reeves, D. B., (2002). The Leader's Guide to Standars: A Blueprint for Educational Equity and Excellence. San Francisco: Jossey-Bass.

Robbins, S. P., (1993). Organizational Behaviour. $6^{\text {th }}$ edition. New Jersey: Prentice Hall. Inc. Internet Edition.

Whitehead, A. N., (1957). The Aims of Education and Other Essays. England: William and Norgate, Ltd. 